\title{
Institutional care for long-term mechanical ventilation in Canada: A national survey
}

\author{
Louise Rose RN PhD ${ }^{1,2,3,4,5}$, Douglas McKim MD FRCPC 6,7 , Sherri Katz MD FRCPC ${ }^{7,8,9}$, David Leasa MD FRCPC ${ }^{10,11}$ \\ Mika Nonoyama RT PhD ${ }^{12}$, Cheryl Pedersen MSc ${ }^{13}$, Monica Avendano MD FRCPC ${ }^{5,14}$, \\ Roger Goldstein MBChB FRCPC 5,13
}

\begin{abstract}
L Rose, D McKim, S Katz, et al. Institutional care for long-term mechanical ventilation in Canada: A national survey. Can Respir J 2014;21(6):357-362.
\end{abstract}

INTRODUCTION: No national Canadian data define resource requirements and care delivery for ventilator-assisted individuals (VAIs) requiring long-term institutional care. Such data will assist in planning health care services to this population.

OBJECTIVE: To describe institutional and patient characteristics, prevalence, equipment used, care elements and admission barriers for VAIs requiring long-term institutional care.

METHODS: Centres were identified from a national inventory and snowball referrals. The survey weblink was provided from December 2012 to April 2013. Weekly reminders were sent for six weeks.

RESULTS: The response rate was $84 \%$ ( 54 of 64), with 44 adult and 10 pediatric centres providing data for 428 VAIs (301 invasive ventilation; 127 noninvasive ventilation [NIV]), equivalent to 1.3 VAIs per 100,000 population. An additional 106 VAIs were on wait lists in 18 centres. More VAIs with progressive neuromuscular disease received invasive ventilation than NIV $(\mathrm{P}<0.001)$; more VAIs with chronic obstructive pulmonary disease $(\mathrm{P}<0.001)$, obesity hypoventilation syndrome $(\mathrm{P}<0.001)$ and central hypoventilation syndrome $(\mathrm{P}=0.02)$ required NIV. All centres used positive pressure ventilators, $21 \%$ diaphragmatic pacing, $15 \%$ negative pressure and $13 \%$ phrenic nerve stimulation. Most centres used lung volume recruitment (55\%), manually $(71 \%)$ and mechanically assisted cough $(55 \%)$. Lack of beds and provincial funding were common admission barriers. CONCLUSIONS: Variable models and care practices exist for institutionalized care of Canadian VAIs. Patient prevalence was 1.3 per 100,000 Canadians.

Key Words: Chronic respiratory failure; Long-term mechanical ventilation; Mechanical ventilation; Outcomes; Rehabilitation; Ventilator-assisted individuals

\section{Les soins institutionnels de la ventilation mécanique prolongée au Canada : un sondage national}

INTRODUCTION : Aucunes données canadiennes ne définissent les besoins en ressources des personnes sous ventilation assistée (PVA) qui requièrent des soins prolongés en établissement ni les soins qui leur sont prodigués. Ces données contribueront à planifier leurs services de santé. OBJECTIF : Décrire les caractéristiques liées aux établissements et aux patients, la prévalence, l'équipement utilisé, les éléments des soins et les obstacles à l'hospitalisation des PVA qui ont besoin de soins institutionnels prolongés.

MÉTHODOLOGIE : Les centres ont été tirés d'une recension nationale et d'aiguillages en « boule de neige ». Le sondage a été accessible de décembre 2012 à avril 2013. Des rappels hebdomadaires ont été envoyés pendant six semaines.

RÉSULTATS : Le taux de réponse s'est élevé à 84 \% (54 sur 64), 44 centres pour adultes et dix centres pédiatriques ayant fourni des données sur 428 PVA ( 301 sous ventilation invasive et 127 sous ventilation non invasive [VNI]), soit 1,3 PVA sur 100000 habitants. Cent six autres PVA étaient sur la liste d'attente de 18 centres. Plus de PVA atteints d'une maladie neuromusculaire dégénérative recevaient une ventilation invasive qu'une VNI $(\mathrm{P}<0,001)$. Plus de PVA atteints d'une maladie pulmonaire obstructive chronique $(\mathrm{P}<0,001)$, du syndrome obésitéhypoventilation $(\mathrm{P}<0,001)$ ou du syndrome d'hypoventilation centrale $(\mathrm{P}=0,02)$ avaient besoin d'une VNI. Tous les centres recouraient à des respirateurs en pression positive, $21 \%$ à la stimulation du diaphragme, $15 \%$ à la pression négative et $13 \%$ à la stimulation du nerf phrénique. La plupart des centres utilisaient le recrutement alvéolaire (55\%) ainsi que la toux assistée manuellement (71\%) et mécaniquement (55\%). Le manque de lits et de financement provincial étaient des obstacles courants à l'admission.

CONCLUSIONS : Les modèles et les pratiques sont variables dans les soins institutionnalisés aux PVA canadiens. On comptait 1,3 patient sur 100000 Canadiens.

\footnotetext{
A dvances in technology and health care, as well as increased availability of supportive care options have contributed to increased survival of adults and children dependent on long-term mechanical ventilation (LTMV) $(1,2)$. Although definitions differ in terms of the duration of ventilation that demarcates LTMV from acute or prolonged mechanical ventilation (3-5), key defining features include physiological stability, care needs that can be managed in a long-term care facility or community setting, and the need for mechanical ventilation on an indefinite basis (6). Patients requiring LTMV are a heterogeneous group with neurological, respiratory and multiorgan system disorders including restrictive and obstructive lung disease, degenerative neuromuscular disease (NMD), thoracic restriction and high spinal cord injury.
}

Supportive care for ventilator-assisted individuals (VAIs) occurs in: complex continuing care hospitals or hospital-based units for those clinically stable but unable to be discharged (7); rehabilitation centres; long-term care centres such as long-term acute care (LTAC) units or skilled nursing facilities, hospices, supported community living, and home health care. While some VAIs are able to reintegrate into the community, others may reside permanently in institutional care locations due either to the intensity of their care needs or the lack of family and paid caregivers (8). Irrespective of the care location, goals of care should focus on maximizing functional capability and quality of life, as well as prevention of morbidity and maintenance of safety.

Numerous studies conducted in various countries describe patient and institutional profiles in acute-care settings such as specialized

${ }^{1}$ Lawrence S Bloomberg Faculty of Nursing, University of Toronto; ${ }^{2}$ Provincial Centre of Weaning Excellence/Prolonged Ventilation Weaning Centre, Toronto East General Hospital; ${ }^{3}$ Sunnybrook Health Sciences Centre; ${ }^{4}$ Li Ka Shing Knowledge Institute, St Michael's Hospital; ${ }^{5}$ West Park Healthcare Centre, Toronto; ${ }^{6}$ The Ottawa Hospital Respiratory Rehabilitation and The Ottawa Hospital Sleep Centre; ${ }^{7}$ University of Ottawa; ${ }^{8}$ Children's Hospital of Eastern Ontario; ${ }^{9}$ Children's Hospital of Eastern Ontario Research Institute, Ottawa; ${ }^{10}$ London Health Sciences Centre; ${ }^{11}$ University of Western Ontario, London; ${ }^{12}$ University of Ontario Institute of Technology, Oshawa; ${ }^{13}$ Centre for Research in Inner City Health, Li Ka Shing Institute, St Michael's Hospital; ${ }^{14}$ University of Toronto, Toronto, Ontario

Correspondence: Dr Louise Rose, Lawrence S Bloomberg Faculty of Nursing, University of Toronto, 155 College Street, Room 276,

Toronto, Ontario M5T IP8. Telephone 416-978-3492, fax 416-978-8222, e-mail louise.rose@utoronto.ca 
TABLE 1

\section{Institutional characteristics}

\begin{tabular}{|c|c|c|}
\hline \multirow[b]{2}{*}{ Characteristic } & \multicolumn{2}{|c|}{ LTMV centre } \\
\hline & $\begin{array}{c}\text { Specialized } \\
(n=34)\end{array}$ & $\begin{array}{l}\text { Nonspecialized } \\
\quad(n=20)\end{array}$ \\
\hline \multicolumn{3}{|l|}{ Institution type } \\
\hline Long-term care facility/nursing home & $9(26)$ & $9(45)$ \\
\hline $\begin{array}{l}\text { Complex continuing care* (stand-alone } \\
\text { institution) }\end{array}$ & $10(29)$ & $3(15)$ \\
\hline $\begin{array}{l}\text { Complex continuing care (located in an } \\
\text { acute care facility) }\end{array}$ & $13(38)$ & - \\
\hline Rehabilitation centre & $2(6)$ & $2(10)$ \\
\hline Pediatric hospice & - & $1(5)$ \\
\hline Acute care unit & - & $5(25)$ \\
\hline \multicolumn{3}{|l|}{ Organizational funding model } \\
\hline Publicly funded & $28(82)$ & $14(70)$ \\
\hline Both public and private funding & $6(18)$ & $5(25)$ \\
\hline Privately funded & - & $1(5)$ \\
\hline \multicolumn{3}{|l|}{ Referral pattern } \\
\hline Regional referral unit & $13(38)$ & $7(35)$ \\
\hline Provincial referral unit & $13(38)$ & $6(30)$ \\
\hline Local population only & $8(24)$ & $7(37)$ \\
\hline Beds, n, median (IQR) & $7(4-15)$ & $3(1-11)$ \\
\hline $\begin{array}{l}\text { Duration of LTMV service provision, } \\
\text { years, median (IQR) }\end{array}$ & $13(7-20)$ & $5(3-12)$ \\
\hline \multicolumn{3}{|l|}{ Population served } \\
\hline$<100,000$ & $6(18)$ & $8(40)$ \\
\hline 100,000 to $<500,000$ & $14(41)$ & $3(15)$ \\
\hline 500,000 to $<1$ million & $3(9)$ & $2(10)$ \\
\hline$\geq 1$ million & $9(26)$ & $3(15)$ \\
\hline Not reported & $2(6)$ & $4(20)$ \\
\hline \multicolumn{3}{|l|}{ Population } \\
\hline Adult & $29(85)$ & $15(75)$ \\
\hline Pediatric & $5(15)$ & $5(25)$ \\
\hline \multicolumn{3}{|l|}{ Province } \\
\hline Ontario & $18(53)$ & $11(55)$ \\
\hline British Columbia & $4(12)$ & $2(10)$ \\
\hline Manitoba & $5(15)$ & - \\
\hline Alberta & $3(9)$ & $2(10)$ \\
\hline Saskatchewan & $2(6)$ & $3(15)$ \\
\hline Quebec & $1(3)$ & $1(5)$ \\
\hline New Brunswick & - & $1(5)$ \\
\hline Newfoundland and Labrador & $1(3)$ & - \\
\hline
\end{tabular}

Data presented as $n$ (\%) unless otherwise indicated. \% totals may sum to more than 100 due to rounding. *Hospital-based care for individuals not ready for hospital discharge but no longer require acute care services. Canadian Institute for Health Information (www.cihi.ca/CIHI-ext-portal/internet/en/ tabbedcontent/types+of+care/hospital+care/continuing+care/cihi018109). LTMV Long-term mechanical ventilation. IQR Interquartile range

respiratory care units $(9,10)$, weaning centres $(11,12)$ or LTAC facilities in the United States (13). Such data for VAIs requiring long-term postacute institutional care are limited. One single-centre retrospective study described outcomes for 50 Canadian patients admitted over a 15-year period to a chronic assisted ventilator care unit (8). The authors reported a program of gradual rehabilitation resulting in functional improvements for most, with low complication rates and reduced health care resource utilization compared with acute care. Our objective was to generate national data to describe institutional characteristics, patient demographics and prevalence, admission criteria, equipment used and key care elements for VAIs requiring long-term institutional care. Such information will identify gaps in service and opportunities for improvement in care provision.

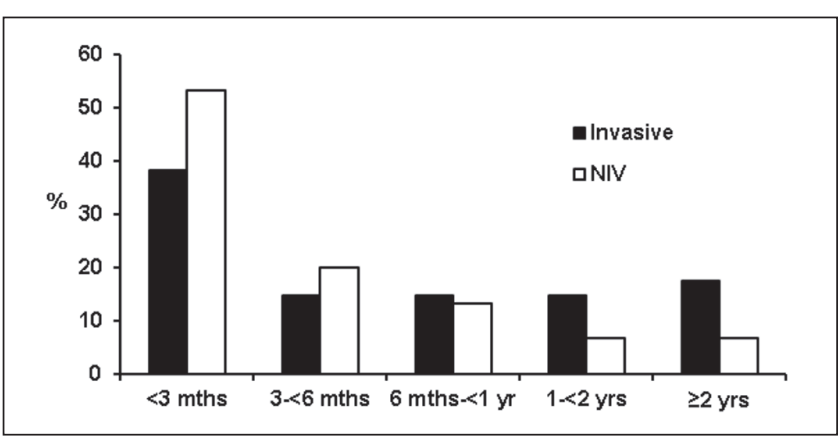

Figure 1) Mean wait time for admission to participating centres. mths Months; NIV Noninvasive ventilation; yr(s) Year(s)

Study design and sample

\section{METHODS}

An exploratory cross-sectional survey was conducted. Eligible sites were those providing care to VAIs dependent on either invasive or noninvasive ventilation (NIV) in a long-term or rehabilitation institutional setting, or in dedicated LTMV beds in an acute setting. Sites that had not provided care to LTMV patients in the preceding 12 months were excluded. For the purposes of the survey, NIV was defined as bilevel or biphasic mask or mouthpiece ventilation and not continuous positive airway pressure (CPAP). Eligible sites were identified during the development of a national provider inventory and through snowball referrals. All sites were screened by telephone to confirm eligibility, seek agreement for questionnaire completion and to identify a survey champion.

Questionnaire development

Informed by an electronic database search (1990 to 2010) of literature relevant to LTMV, 10 team members representing medicine, nursing, respiratory and physical therapy, generated and iteratively refined questionnaire domains, items and response formats. Using Snap Professional Software (snapsurveys.com, United Kingdom), a webbased questionnaire piloted by four LTMV experts (national and international) was developed. Experts were asked to rate and comment on questionnaire comprehensiveness, redundancy, clarity, face validity, completion time and the number of health care team members needed to gather required information. Final modification based on expert feedback resulted in a questionnaire comprising seven domains: institution/service provision characteristics; patient characteristics; selection criteria and referral; equipment; key elements of care; training and education; and liaisons and transitions.

\section{Questionnaire administration}

An independent survey unit (www.stmichaelshospital.com/crich/ about/) was contracted to manage questionnaire administration and data collection. The online questionnaire was provided from December 2012 to April 2013 via a secure weblink to site self-nominated survey champions (medical directors, nurse managers, physicians or respiratory therapists). Respondents were directed to access interprofessional team members to obtain data to assist with questionnaire completion if necessary. Weekly telephone and e-mail reminders were sent for six weeks, with two 'last chance' reminders in April 2013.

\section{Ethical considerations}

Research Ethics Boards of the University of Toronto and St Michael's Hospital (Toronto, Ontario) approved the study. Participation was voluntary and consent implied by questionnaire return.

\section{Statistical analyses}

Results were examined using descriptive statistics including the Sharpiro-Wilk test for normality. Continuous variables were summarized as median and interquartile range (IQR) due to data distribution, and categorical variables as frequencies and proportions. Responses from LTMV specialized centres (centres with designated beds to 
TABLE 2

\section{Patient characteristics}

\begin{tabular}{lccc}
\hline & \multicolumn{2}{c}{ Ventilation } & \\
\cline { 2 - 3 } & $\begin{array}{c}\text { Invasive } \\
\text { (n=301) }\end{array}$ & $\begin{array}{c}\text { Noninvasive } \\
\text { (n=127) }\end{array}$ & P \\
\hline Primary disorders & & & \\
Progressive degenerative NMD & $136(45)$ & $29(23)$ & $<0.01$ \\
Spinal cord injury & $38(13)$ & $15(12)$ & 0.87 \\
Obesity hypoventilation syndrome & $2(1)$ & $33(26)$ & $<0.01$ \\
COPD & $10(3)$ & $20(16)$ & $<0.01$ \\
Post-polio syndrome & $13(4)$ & $3(2)$ & 0.41 \\
Central hypoventilation syndrome & $7(2)$ & $9(7)$ & 0.02 \\
Chest wall restriction & $9(3)$ & $5(4)$ & 0.57 \\
ARDS and/or ICU-acquired weakness & $4(1)$ & $1(1)$ & 1.0 \\
Other* & $16(5)$ & $9(7)$ & 0.50 \\
Not reported & $66(22)$ & $2(2)$ & $<0.01$ \\
Age range, years & & & \\
<18 & $32(11)$ & $20(16)$ & 0.15 \\
18-29 & $32(11)$ & $12(10)$ & 0.86 \\
30-65 & $107(36)$ & $60(48)$ & 0.03 \\
$>65$ & $59(20)$ & $23(18)$ & 0.78 \\
Not reported & $71(24)$ & $12(9)$ & $<0.01$ \\
\hline
\end{tabular}

Data presented as $n(\%)$ unless otherwise indicated. Note: totals across categories do not sum because some institutions were unable to provide data. "Other comprise: Invasive ventilation - metabolic disorders $(n=3)$, failure to wean, cause unspecified $(n=3)$, West Nile virus $(n=2)$, infantile tracheal stricture, brainstem stroke, neurological injury, hydrocephalus/seizure disorder, Arnold-Chiari malformation/spina bifida, Guillain Barré and ependymal abnormality (all $n=1$ ); Noninvasive ventilation - congestive heart failure and chronic obstructive pulmonary disease (COPD) exacerbation $(n=3)$, stroke, airway obstruction, congenital myasthenia gravis, cerebral palsy (all $n=1$ ). ARDS Acute respiratory distress syndrome; ICU Intensive care unit; NMD Neuromuscular disorder

provide care to VAIs requiring either invasive and NIV in the long term) were compared with non-LTMV specialized centres (providing only NIV, respite or short-term placements, or acute care units where VAIs were present long-term because no alternative location was available) as well as adult and pediatric centres, using $\chi^{2}$ or Fisher' exact tests depending on individual cell size or Mann-Whitney tests. Due to missing responses, denominators varied. Analyses were performed using SPSS version 22 (IBM Corporation, USA).

\section{RESULTS}

A total of 120 centres were contacted, of which 64 were eligible. Reasons for ineligibility included: 45 of 56 (80\%) did not provide care to VAIs; nine of $56(16 \%)$ had not admitted a VAI within the past 12 months; and two (4\%) were acute care centres that did not provide long-term care to VAIs. The survey response rate was $84 \%$ (54 of 64).

\section{Unit characteristics}

Surveys for 44 adult and 10 pediatric centres were returned. Of these 54 centres, $34(63 \%)$ were categorized as LTMV specialized centres and $20(37 \%)$ as non-LTMV specialized centres, the latter of which included 15 of $20(75 \%)$ providing only NIV, respite or short-term placements, and five of 20 (25\%) that were acute-care units with VAIs in long-term residence. The most frequent admission criteria for specialized LTMV centres were lack of weaning potential (29 of 32 [91\%]), medical stability (28 of 32 [88\%]) and the need for long-term NIV (23 of 32 [72\%]). Five hundred seventy-nine LTMV-capable beds were identified (81 in pediatric centres). The median centre size was 7 (IQR 4 to 15 ) beds in specialized LTMV centres and 3 (IQR 1 to 11) beds in nonspecialized centres. The median duration of service as an institutional provider was 11 (IQR 5 to 18) years overall with LTMV specialized centres being established longer than non-LTMV centres $(P=0.01)$ (Table 1). Of the 46 centres reporting their current wait list, 28 had no

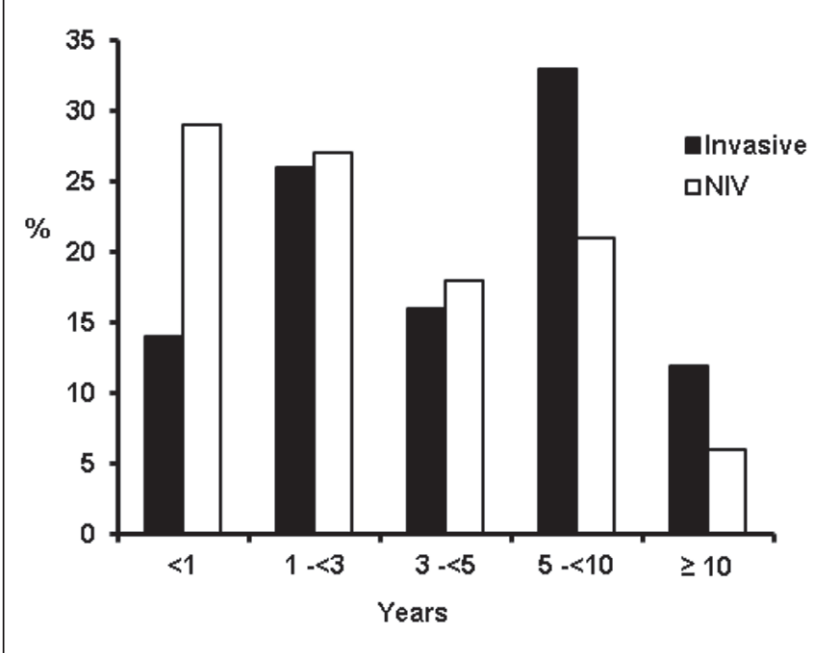

Figure 2) Mean length of stay in participating centres. NIV Noninvasive ventilation

wait list and 18 reported a total of 106 VAIs (89 invasive and 17 NIV) waiting for admission. Most centres had only one to five VAIs on their wait list; one specialized centre in Ontario had 40 VAIs waiting for admission. The average wait time for admission according to ventilation type is shown in Figure 1. Wait times exceeding one year were reported by 11 (32\%) centres for invasively ventilated and four (13\%) centres for NIV VAIs.

\section{Patient characteristics}

Responding centres provided data on 428 VAIs, of whom 301 (32 pediatric) were receiving invasive ventilation and 127 (20 pediatric) NIV. Based on the 2011 Canadian census population (14), the estimated prevalence of VAIs in institutional care was 1.3 per 100,000 population. The estimated prevalence of pediatric VAIs $<18$ years of age was 0.8 per 100,000 population. Primary diagnoses resulting in invasive ventilation and NIV differed. More VAIs with progressive NMD received invasive ventilation than NIV $(\mathrm{P}<0.001)$, whereas more VAIs with chronic obstructive pulmonary disease $(\mathrm{P}<0.001)$, obesity hypoventilation syndrome $(\mathrm{P}<0.001)$ and central hypoventilation syndrome $(\mathrm{P}=0.02)$ required NIV. Patient characteristics are summarized in Table 2 . The mean duration of stay according to ventilation type is shown in Figure 2. Nineteen of the 43 (44\%) reporting centres indicated this was $>5$ years for invasively ventilated individuals. Fifty-three VAIs in 24 centres commenced invasive ventilation over the previous 12 months; 41 VAIs were newly commenced on NIV in 19 centres.

\section{Ventilators and interfaces}

All centres provided care to VAIs using positive pressure ventilators; use of other technologies, such as negative pressure ventilators $(n=8[15 \%])$, diaphragmatic pacing $(n=11[21 \%])$ and phrenic nerve stimulation $(n=7[13 \%])$ was infrequent. Of the 31 adult and nine pediatric centres providing care to tracheostomized patients, 30 (97\%) adult and seven $(78 \%)$ pediatric centres used cuffed tubes, and 25 (81\%) adult and seven $(78 \%)$ pediatric used uncuffed tubes. Use of speaking valves was less common: $16(52 \%)$ adult and three (33\%) pediatric centres. Of the 34 adult and eight pediatric centres providing NIV, 29 (85\%) adult and five $(63 \%)$ pediatric centres used orofacial masks, and 23 (68\%) adult and five $(63 \%)$ pediatric centres used nasal masks. Oral mouth pieces were used by $14(41 \%)$ adult and two $(25 \%)$ pediatric centres. Two centres did not report on the interfaces used.

\section{Key care elements}

Airway clearance and progressive ventilator-free breathing: $O f$ the 51 centres reporting on cough augmentation techniques, most $(n=30$ [73\%]) adult centres used manually assisted cough; fewer reported 


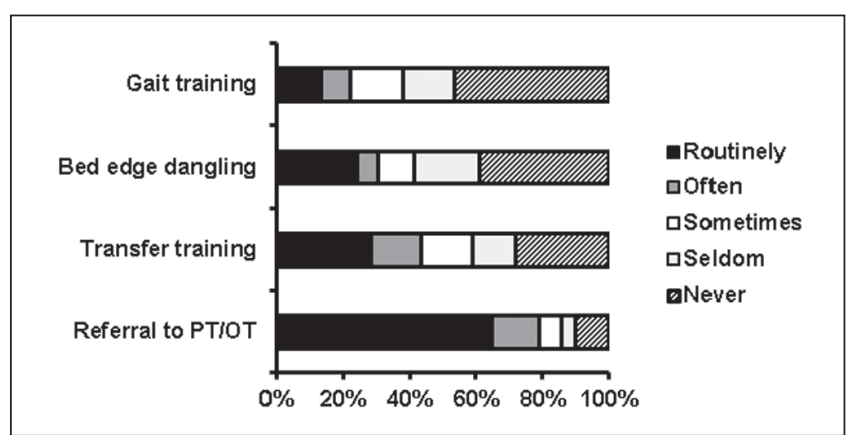

Figure 3) Strategies to promote functional independence. OT Occupational therapy; PT Physiotherapy

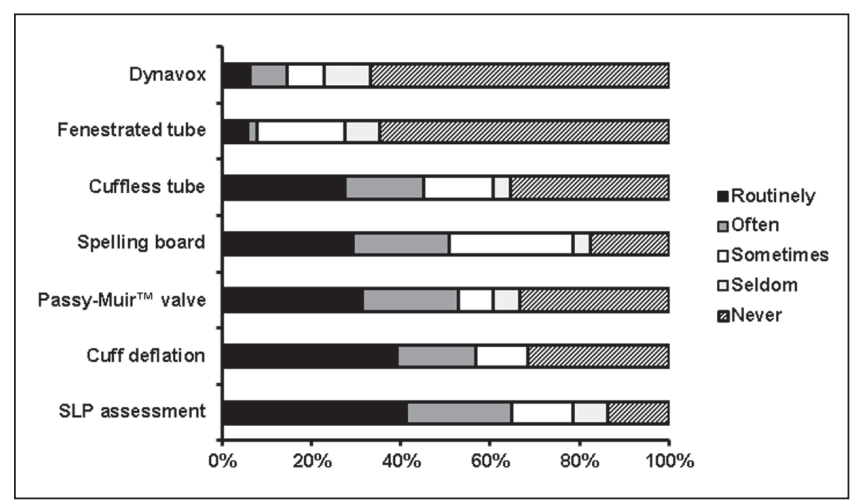

Figure 4) Strategies to promote communication. SLP Speech-language pathology

using mechanical in-exsufflation $(n=23$ [56\%]) and lung volume recruitment $(n=21[51 \%])$. In pediatric centres, seven $(70 \%)$ used lung volume recruitment, six (60\%) manually assisted cough and five (50\%) mechanical in-exsufflation. Availability of these techniques was more common in specialized LTMV centres (all P values $<0.05$ ) but did not differ between adult and pediatric centres. Of the 42 centres providing care to tracheostomized patients, $45 \%$ reported having a written protocol for minimally invasive suctioning and 29 (69\%) had a written protocol for deep suctioning. Only one centre identified a set suctioning frequency; all others indicated that it was performed on an as-needed basis. Maximizing ventilator-free breathing using graduated time off the ventilator was used by 26 of 46 (57\%) centres, with reduced ventilator settings for a prescribed duration being used by $19(41 \%)$. Both strategies were more commonly used in LTMV centres $(\mathrm{P}<0.01)$.

Mobility, communication and nutrition: Most (31 of 48 [65\%]) centres routinely referred VAIs to physical and occupational therapy, although use of other strategies to promote functional independence varied (Figure 3). Referral to speech-language pathology for communication assessment was routine in 21 of $51(41 \%)$ centres (Figure 4$)$. In most (46 of 49 [94\%]) centres, VAIs were assessed by a dietician, with $34(69 \%)$ centres stating that a protocol for maximizing nutritional status was available.

Prevention of complications, symptom assessment and psychosocial support: Deep vein thrombosis prophylaxis was routinely administered in 23 of 39 (59\%) adult centres. Figure 5 shows the frequency of other strategies used to prevent complications associated with mechanical ventilation and immobility in adult and pediatric centres. Most (36 of 49 [74\%]) centres used an objective tool to assess pain. Dyspnea (26 of 52 [50\%]), anxiety (25 of 52 [48\%]) and sleep (19 of 48 [40\%]) were also assessed.

Routine referral to social work and psychiatry occurred in 26 of $49(53 \%)$ and seven of $49(14 \%)$ centres, respectively. Twenty-four (49\%) centres routinely held group activities and 16 of $49(33 \%)$

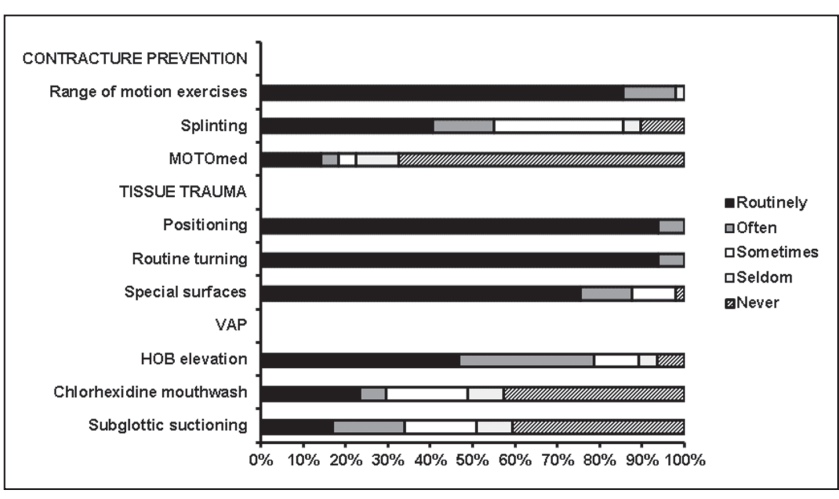

Figure 5) Prevention of complications. HOB Head of bed; VAP Ventilator-acquired pneumonia

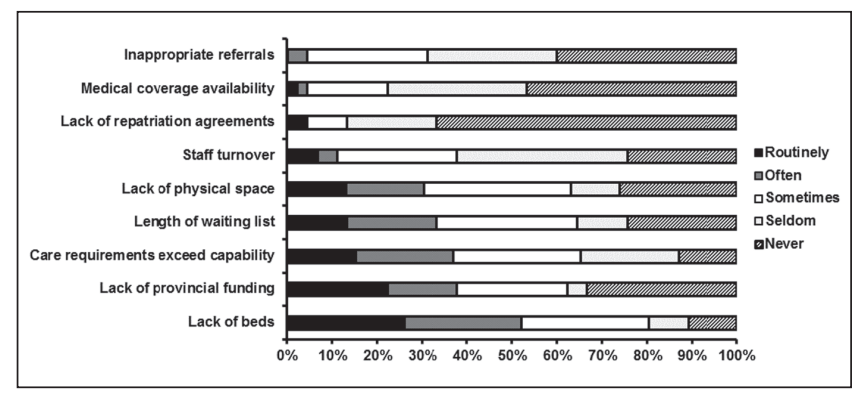

Figure 6) Barriers to admission

routinely facilitated outings to promote psychosocial health. Family meetings were held by all centres, although the frequency of these ranged from monthly to once per year. Staff debriefing sessions were provided by 45 of 49 (92\%) centres.

\section{Barriers to admission}

Lack of beds, lack of provincial funding and care requirements that exceeded the institution's capacity were the three top barriers to admission (Figure 6). However, 15 centres from seven provinces stated they did not experience provincial funding as a barrier. Barriers most commonly never experienced were inability to secure repatriation agreements if a VAI was to become acutely unstable (30 of 45 [67\%]), lack of medical coverage (21 of 45 [47\%]) and inappropriate referrals (18 of 45 [40\%] centres).

\section{DISCUSSION}

Our study was the first to comprehensively describe service provision for both adult and pediatric VAIs requiring long-term institutional care in Canada. Consistent with the European model of care, health services in Canada are primarily publicly funded at the provincial level (15). We found an estimated prevalence of 1.3 VAIs in institutional care per 100,000 population and 0.8 pediatric VAIs per 100,000 children $<18$ years of age. This does not account for individuals located in intensive care units (ICUs) or those receiving ventilatory support in the community. In a contemporaneous survey, we identified that there were an additional 42 patients ventilated $\geq 6$ months in the ICU and that $11 \%$ of the Canadian acute care ventilator bed capacity was occupied by medically stable patients ventilated for $>21$ days (16). Participating centres identified an additional 106 VAIs on their wait lists, some of whom could have been resident in ICUs at this time. The size and length of wait lists, as well as the location of VAIs in acute care units support the perception that lack of beds and associated funding issues are key barriers to their placement in long-term institutional care.

Although individuals dependent on ventilation in the long term are generally deconditioned and have limited mobility, we found only 
variable uptake of interventions that promote physical functioning and those designed to prevent complications such as contractures, tissue trauma and ventilator-acquired pneumonia. To our knowledge, there are no guidelines for overall rehabilitation specific to these individuals (17), although there are published recommendations for respiratory physiotherapy (18-20). Development of such guidelines with inclusion of both physical and respiratory rehabilitation strategies, such as airway clearance and ventilator-free breathing, may encourage functional independence, improve quality of life and prevent complications. We found only variable adoption of strategies to improve psychological well-being and communication, the latter being an important contributor to the former for tracheostomized patients (21). Similarly, depression and decreased emotional well-being are common experiences for VAIs that need to be addressed (22-25).

The relatively small proportion of VAIs requiring institutionalized care and receiving NIV likely reflects the success of home ventilation training programs that enable these patients to either remain at home or to successfully transition back to the community after ventilator support has been established. The most comprehensive characterization of home ventilation - the Eurovent study conducted in 2001 to 2002 - reported an estimated prevalence of 6.6 VAIs per 100,000 population in 16 countries (26). This survey also reported that approximately $38 \%$ of users required ventilation for lung/airway indications whereas our survey found few VAIs received ventilation for this indication. In a contemporaneous survey of Canadian service providers to VAIs living at home, we identified $4334 \mathrm{VAIs}$, with progressive NMD and spinal cord injury being the most frequent indications for ventilation; chronic obstructive pulmonary disease and acute respiratory distress syndrome were infrequent reasons (unpublished data). Despite profound exercise and functional limitations experienced by acute respiratory distress syndrome survivors (27), few appear to require ventilation in the long term.

Comparison of our prevalence estimates of VAIs in long-term institutional care and characterization of key care elements with those of other countries is problematic due to differences in health care models, variable cohort definitions and a lack of published studies from similar institutions. In Europe, options for postacute institutional care for VAIs include chronic assisted ventilator care units, inpatient rehabilitation centres and ventilator-capable skilled nursing facilities (28). The availability and type of long-term care facility varies across and within European countries and may be influenced by availability of home ventilation centres. In the United States, LTACs are another possible care venue (2). Although several studies from LTACs report VAI and care characteristics $(13,29,30)$, these may not be comparable populations because LTACs are acute care hospitals with average lengths of stay exceeding 25 days (31), provide care of an intensity not found in the institutions participating in our study, provide specialized rehabilitation and weaning for VAIs ventilated for $>21$ days, and generally do not admit patients known to be unweanable, alhough some LTACs are colocated with a ventilatorcapable skilled nursing facility.

Strengths of our study include rigorous survey development and meticulous follow-up, yielding a response rate of $84 \%$ and provision of data representative of centres across Canada. Similar to any self-report survey, ours was limited by descriptions of reported as opposed to actual practice of key care elements, which may be inaccurate due to inadequate knowledge or social desirability bias. Characterization of primary diagnoses resulting in ventilation was not validated by the treating physician and may be a source of inaccuracy. Additionally, our estimate of patient prevalence may be lower than the actual prevalence due to nonresponse from 10 centres and the possibility that we did not identify all centres across Canada. Future research involving this population is needed to further explore reasons for admission delay; the relationship between specific diagnoses and care practices; the type of respiratory assessments needed to ascertain the ability to tolerate increased time off the ventilator and potential for weaning; and staffing models for LTMV centres.

\section{CONCLUSION}

We found variable models for institutionalized care of VAIs in Canada. Patient prevalence was 1.3 per 100,000 Canadians, although this does not account for VAIs who remain resident in ICUs. There is a need for care pathways and guidelines that address physical and psychosocial rehabilitation for individuals requiring LTMV because strategies to promote well-being, functional independence and communication were used variably. Size and length of wait lists, location of VAIs in acute care units, lack of beds and associated funding were barriers to admission. The above information will be of value to those who fund and deliver health care for ventilator-dependent individuals.

ON BEHALF OF THE CANUVENT GROUP: Reshma Amin, The Hospital for Sick Children; Monica Avendano, West Park Healthcare Centre; Sandra Dial, Montreal Chest Institute; Eddy Fan, Mount Sinai Hospital; Ian Fraser, Toronto East General Hospital; Robert Fowler, Sunnybrook Health Sciences Centre; Roger Goldstein, West Park Healthcare Centre; Sherri Katz, Children's Hospital of Eastern Ontario; Judy King, University of Ottawa; David Leasa, London Health Sciences Centre; Cathy Mawdsley, London Health Sciences Centre; Douglas McKim, Ottawa Hospital; Mika Nonoyama, University of Toronto; Jeremy Road, Provincial Respiratory Outreach Program, Vancouver Coastal Health; Louise Rose, University of Toronto; Gordon Rubenfeld, Sunnybrook Health Sciences Centre.

DISCLOSURES: The authors have no financial or nonfinancial competing interests to declare.

AUTHOR CONTRIBUTIONS: Conception and design of the study: LR, DM, SK, DL, MN, MA, RG; Acquisition, LR, CP; analysis and interpretation of data: all authors; Drafting the article or revising it critically for important intellectual content: all authors. LR is the guarantor of the article, taking responsibility for the integrity of the work as a whole, from inception to published article.

INSTITUTION: This work was conducted at the Centre for Research in Inner City Health at St Michael's Hospital and the University of Toronto.

FUNDING: The work was funded by a grant from the Partnerships for Health Systems Improvement competition of the Canadian Institutes of Health Research.

\section{REFERENCES}

1. McDougall C, Adderley R, Wensley D, Seear M. Long-term ventilation in children: Longitudinal trends and outcomes. Arch Dis Child 2013;98:660-5.

2. Cox C, Carson S. Medical and economic implications of prolonged mechanical ventilation and expedited post-acute care. Semin Respir Crit Care Med 2012;33:357-61.

3. Make B, Hill N, Goldberg A, et al. Mechanical ventilation beyond the intensive care unit: Report of a consensus conference of the American College of Chest Physicians. Chest 1998;113:289S-344S.

4. Wallace CJ, Oniki T, Bailey P, Clemmer TP. Implementation and testing of a respiratory failure care process model for patients with long-term mechanical ventilation. Proc AMIA Symp 1998;1093.

5. Jardine E, Wallis C. Core guidelines for the discharge home of the child on long-term assisted ventilation in the United Kingdom. UK Working Party on Paediatric Long Term Ventilation. Thorax 1998;53:762-7.

6. Rose L, Fowler R, Katz S, Leasa D, McKim D. Definitional criteria for patient transitions relevant to prolonged and long-term mechanical ventilation: A Delphi study. Can Respir J May 2, 2014 (E-pub ahead of print).

7. Canadian Institute of Health Information. Continuing care. $<$ www.cihi.ca/CIHI-ext-portal/internet/en/tabbedcontent/ types+of +care/hospital+care/continuing+care/cihi018109> (Accessed February 28, 2014). 
8. Wijkstra P, Avendano M, Goldstein R. Inpatient chronic assisted ventilatory care: A 15-year experience. Chest 2003;124:850-6.

9. Aboussouan L, Lattin C, Vijay V. Determinants of time-to-weaning in a specialized respiratory care unit. Chest 2005;128:3117-26.

10. Ceriana P, Delmastro M, Rampulla C, Nava S. Demographics and clinical outcomes of patients admitted to a respiratory intensive care unit located in a rehabilitation center. Respir Care 2004:48:670-6.

11. Hannan LM, Tan S, Hopkinson K, et al. Inpatient and long-term outcomes of individuals admitted for weaning from mechanical ventilation at a specialized ventilation weaning unit. Respirology 2013;18:154-60.

12. Rose L, Fraser I. Patient characteristics and outcomes of a provincial prolonged-ventilation weaning centre: A retrospective cohort study. Can Respir J 2012;19:216-20.

13. Scheinhorn DJ, Hassenpflug MS, Votto JJ, et al. Post-ICU mechanical ventilation at 23 long-term care hospitals a multicenter outcomes study. Chest 2007;131:85-93.

14. Statistics Canada 2011 Census profile. <www12.statcan.gc.ca/ census-recensement/index-eng.cfm> (Accessed February 28, 2014).

15. Centre for Health Services and Policy Research Post-acute care. The University of British Columbia < http://healthcarefunding.ca/ current-funding/post-acute-care/> (Accessed April 8, 2014).

16. Rose L, Fowler R, Fan E, et al. Prolonged mechanical ventilation in Canada: A national survey. Intensive Care Med 2013;39:A0885 (Abst).

17. Martin U, Hincapie L, Nimchuk M, et al. Impact of whole-body rehabilitation in patients receiving chronic mechanical ventilation. Crit Care Med 2005;33:2259-65.

18. McKim D, Road J, Avendano M, et al. Home mechanical ventilation: A Canadian Thoracic Society clinical practice guideline. Can Respir J 2011;18:197-215.

19. Windisch W, Walterspacher S, Siemon K, Geiseler J, Sitter H; German Society for Pneumology. Guidelines for non-invasive and invasive mechanical ventilation for treatment of chronic respiratory failure. Pneumologie 2010;64:640-52.

20. ACI Respiratory Network. Domiciliary non-invasive ventilation in adult patients: A consensus statement. Agency for Clinical
Innovation, Chatswood. <www.aci.health.nsw.gov.au/_data/assets/ pdf_file/0008/159794/ACI-NIV-guidelines.pdf\#zOom=100> (Accessed April 8, 2014).

21. Laakso K, Markström A, Hartelius L. Communication and quality of life in individuals receiving home mechanical ventilation. Int J Ther Rehabil 2009;16:648-55.

22. Charlifue S, Apple D, Burns S, et al. Mechanical ventilation, health, and quality of life following spinal cord injury. Arch Phys Med Rehabil 2011;92:457-63.

23. Rousseau M, Pietra S, Blaya J, Catala A. Quality of life of ALS and LIS patients with and without invasive mechanical ventilation. J Neurol 2011;258:1801-4.

24. Vianello A, Arcaro G, Palmieri A, et al. Survival and quality of life after tracheostomy for acute respiratory failure in patients with amyotrophic lateral sclerosis. J Crit Care 2011;26:e7-14.

25. Jubran A, Lawm G, Kelly J, et al. Depressive disorders during weaning from prolonged mechanical ventilation. Intensive Care Med 2010;36:828-35.

26. Lloyd-Owen S, Donaldson G, Ambrosino N, et al. Patterns of home mechanical ventilation use in Europe: Results from the Eurovent survey. Eur Respir J 2005;25:1025-31.

27. Herridge M, Tansey C, Matté A, et al; Canadian Critical Care Trials Group. Functional disability 5 years after acute respiratory distress syndrome. N Engl J Med 2011;364:1293-304.

28. Vianello A, Ambrosino N. Clinical settings for ventilator-assisted individuals - when and why - LTAC-SNF-CAVC. In: Ambrosino N, Goldstein R, eds. Ventilatory Support for Chronic Respiratory Failure. New York: Informa Healthcare USA, Inc, 2008:181-9.

29. Scheinhorn DJ, Hassenpflug MS, Votto JJ, et al. Ventilatordependent survivors of catastrophic illness transferred to 23 long-term care hospitals for weaning from prolonged mechanical ventilation. Chest 2007;131:76-84.

30. Divo MJ, Murray S, Cortopassi F, Celli BR. Prolonged mechanical ventilation in Massachusetts: The 2006 prevalence survey. Respir Care 2010;55:1693-8.

31. Kahn J, Werner R, David G, Ten Have T, Benson N, Asch D. Effectiveness of long-term acute care hospitalization in elderly patients with chronic critical illness. Med Care 2013;51:4-10. 


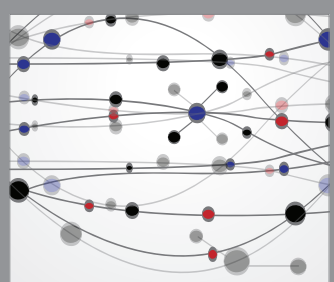

The Scientific World Journal
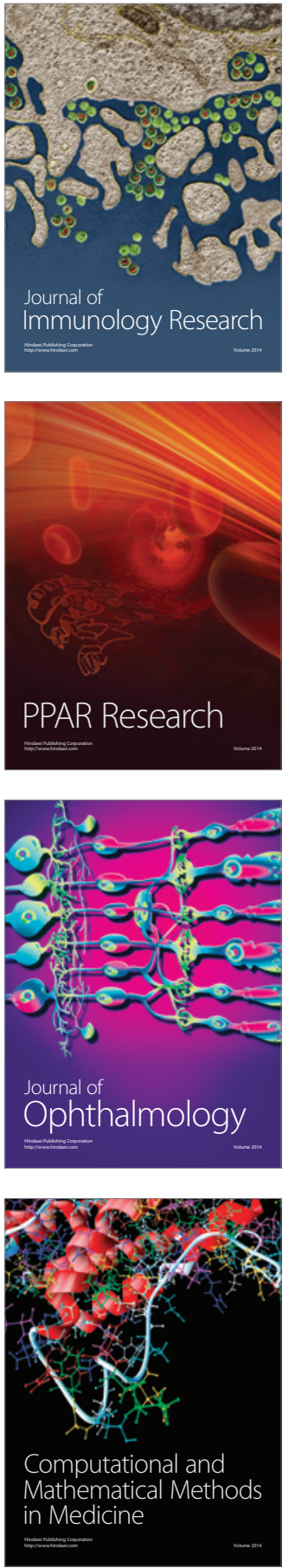

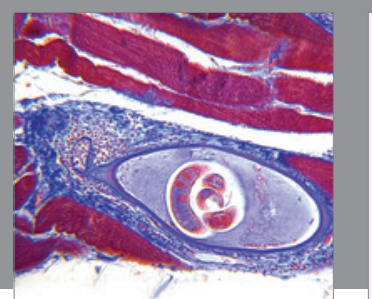

Gastroenterology Research and Practice

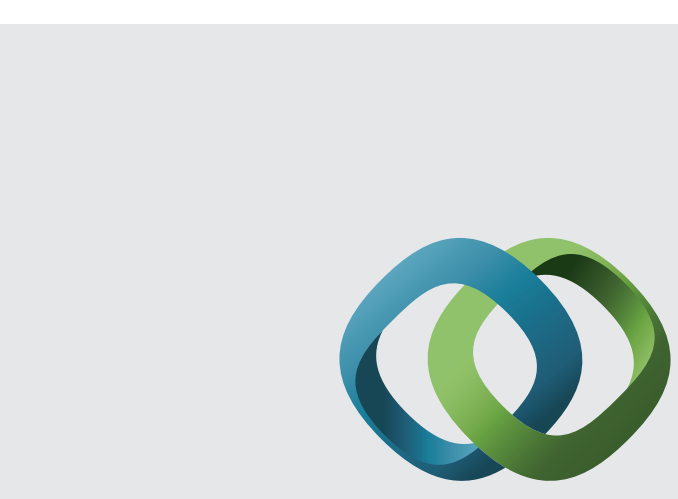

\section{Hindawi}

Submit your manuscripts at

http://www.hindawi.com
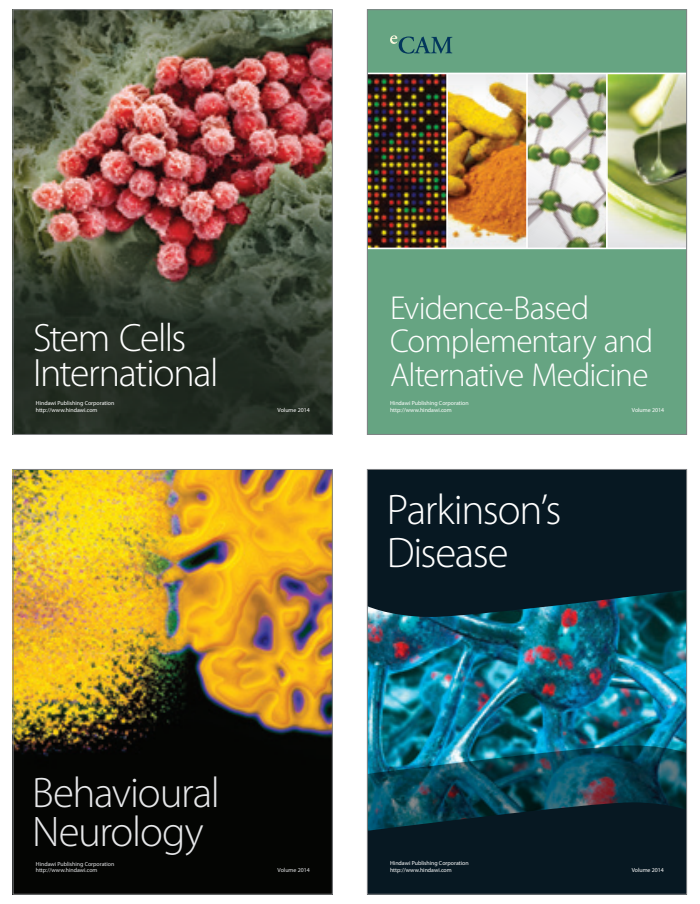
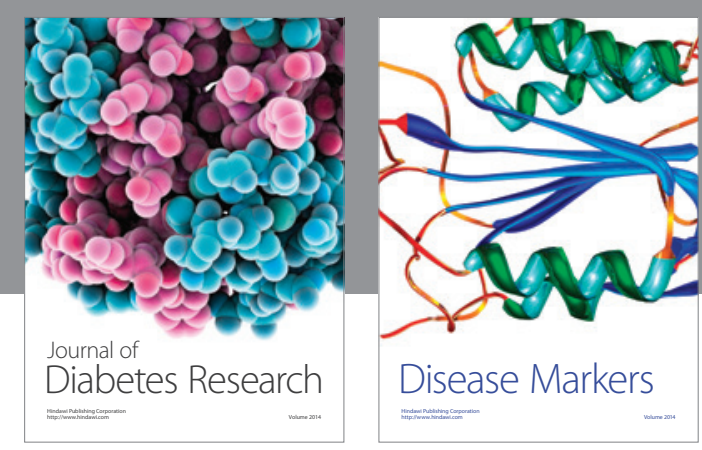

Disease Markers
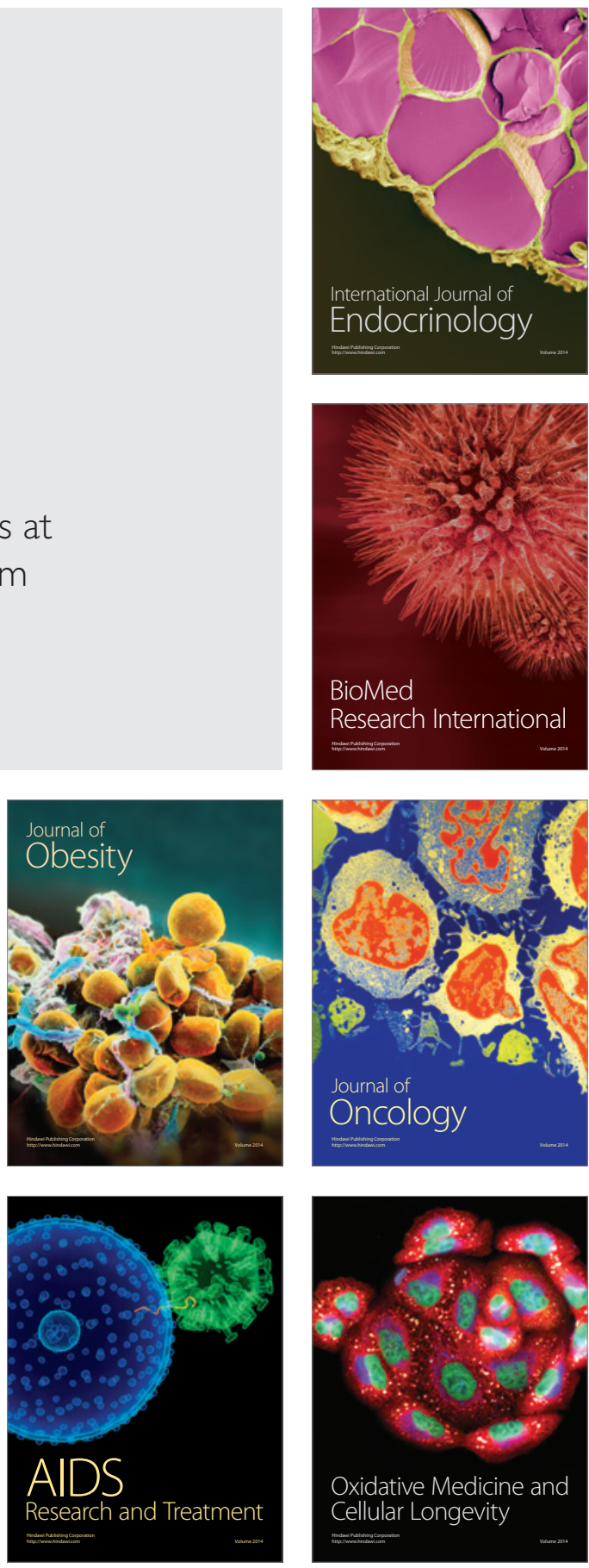